\title{
Pljushtchia prima, new moth genus and species from Tadjikistan (Lepidoptera: Geometridae)
}

\author{
JAAN VIIDALEPP $^{1}$ and IGOR KOSTJUK ${ }^{2}$ \\ ${ }^{1}$ Institute of Zoology and Botany, Estonian Agricultural University, Riia St. 181, EE-51014 Tartu; e-mail: jaan@zbi.ee \\ ${ }^{2}$ Zoological Museum, Kiev Taras Shevchenko National University, Vladimirskaja 60, 01033 Kiev, Ukraine; \\ e-mail: ikostjuk@univ.kiev.ua
}

Key words. Geometridae, Larentiinae, Pljushtchia prima gen. n. \& sp. n., Heterothera, Pennithera, Protothera, Thera, taxonomy

\begin{abstract}
A new genus and species of geometrid moths from Tadjikistan is described and its position in the taxonomic structure of the subfamily Larentiinae is analysed. The new genus is grouped, based on the parsimony analysis of 38 morphological characters, to coniferous-feeding genera of the tribe Cidariini as follows: (Thera (Pennithera (Protothera (Pljushtchia gen. n. Heterothera)))). Pljushtchia is characterised by the antennae, unipectinate in males and flat, serrate in females, by a reduced haustellum, the venation of wings and the structure of the genitalia. The Thera firmata species group is validated as a genus Protothera. The tribe Cidariini includes four groups of related genera and is most speciose in southeastern Asia.
\end{abstract}

\section{INTRODUCTION}

Late in the eighties of the previous century, the first author was presented four specimens of an unknown Larentiine moth for determination by I. Pljushtch. Having just finished a review of the geometrid moths in Central Asian mountains (Viidalepp, 1988), he understood that this specimen belonged to an undescribed species (Fig. 1). Interestingly, some special characters of the new species appeared unprecedented for a Larentiine moth and required a careful study of eastern and southern Palearctic genera to find a possible sister-group. The search in larger European Lepidoptera collections allowed a study of all Palearctic genera of the subfamily, but was not successful for Pljushtchia, until an additional series of this new moth collected by Yu.L. Shtshetkin was found in the collection of the Zoologisches Staatsmuseum München by I. Kostjuk. The description of the new species is given and an analysis of its character spectrum is added in the present paper.

The positioning of the new genus in the system of the subfamily Larentiinae is the second goal of the paper. The genera of Larentiinae, described in the XIXth and early XXth centuries, are founded on their unique characters, be it apomorphic or plesiomorphic, or on diagnostic combinations of characters. The recent paradigm stresses the need for search of synapomorphies to build up the phylogeny of related groups, and this is taken into account below.

It is problematic to place plesiomorphic species - that Pljushtchia prima seems to be - on a broader scale. The peculiar combination of regressive and autapomorphic characters in Pljushtchia aggravates the search for its possible sister-group. There is no especially supporting evidence for the phylogenetic relationships. Available evidence indicates only that this species does not fit with any of the existing genera.

\section{MATERIAL AND METHODS}

Adult Larentiinae moths have been studied from the following museums:

The Natural History Museum, London (NHM); Nature Museum of Humboldt University, Berlin (NMHU); Institute of Zoology and Botany at Estonian Agricultural University, Tartu, Estonia (ZBI); Zoologisches Forschungsinstitut und Museum Alexander König, Bonn (ZFMK); Zoological Institute in St. Petersburg (ZISP), Zoological Museum of Kiev Taras Shevchenko National University (ZMKU), Zoologische Staatssammlung, München (ZSM) and Zoological Museum of Copenhagen University (ZMUC).

For cladistic analysis, dry pinned moths and slides of genitalia (in euparal or glycerol) from the lepidopterological collection of ZBI were studied. The species with both male and female specimens available were selected for study. Genitalic preparations were made following conventional procedures (Meijerman et al., 2000). Characters are scored with the primitive state as zero for convenience. The following taxa were examined and discussed for coding the characters for cladistic analysis (see Appendix):

Chloroclysta siterata (Hufnagel, 1767)

Chloroclysta miata (Linnaeus, 1758)

Cidaria fulvata (Forster, 1775)

Coenotephria salicata (Hübner, [1799])

Colostygia aptata (Hübner, [1813])

Colostygia olivata ([Denis \& Schiffermüller], 1775)

Cosmorhoe ocellata (Linnaeus, 1758)

Dysstroma citrata (Linnaeus, 1761)

Ecliptopera silaceata ([Denis \& Schiffermüller], 1775)

Ecliptopera capitata (Herrich-Schäffer, [1839])

Electrophaes corylata (Thunberg, 1792)

Eulithis testata (Linnaeus, 1758)

Eustroma reticulata ([Denis \& Schiffermüller], 1775)

Gandaritis fixseni (Bremer, 1864)

Gandaritis pyraliata ([Denis \& Schiffermüller], 1775)

Heterothera serraria (Lienig, 1846)

Heterothera kurentzovi Choi, Viidalepp et Vasjurin, 1998

Hysterura declinans (Staudinger, 1897)

Lampropteryx suffumata ([Denis \& Schiffermüller], 1775) 


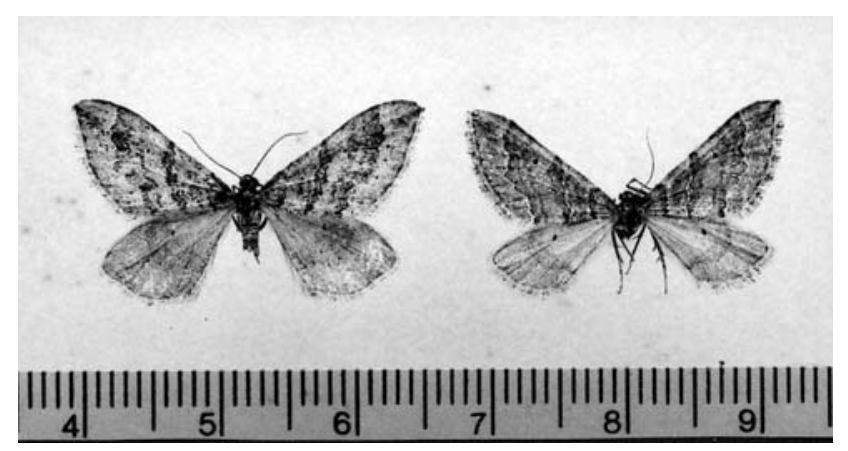

Fig. 1. Pljushtchia prima Viidalepp \& Kostjuk, male (left), female (right). Wing span, 24 and $22 \mathrm{~mm}$, respectively.

\section{Lobogonodes erectaria (Leech, 1897)}

Nebula nebulata (Treitschke, 1828)

Pennithera comis (Butler, 1879)

Pennithera subcomis (Inoue, 1978)

Pljushtchia prima Viidalepp \& Kostjuk, gen. et sp. n.

Polythrena coloraria (Herrich-Schäffer, 1855)

Protothera firmata (Hübner, [1822])

Protothera ulicata (Rambur, 1834)

Stamnodes depeculata (Lederer, 1870)

Thera variata ([Denis \& Schiffermüller], 1775)

Thera obeliscata (Hübner, [1787])

Trichodezia kindermanni (Bremer, 1864)

Xenortholitha propinguata (Kollar, 1844)

\section{RESULTS}

\section{Genus Pljushtchia Viidalepp \& Kostjuk, gen. n.}

Type species: Pljushtchia prima Viidalepp \& Kostjuk, sp. n.

\section{Description}

Frons strongly bulged, projecting about one-half of the diameter of eye. Eyes in female smaller than in male. Palpi shorter than diameter of eye, haustellum reduced. Male antennae shortly unipectinate up to apical segments, pectinations a little longer than diameter of flagellum; female antennae flattened and saw-toothed in middle part. Mesotibia with one pair of spurs, hind tibia with two pairs. Hind leg with tarsus about one fourth shorter than tibia. Venation (Fig. 2): forewings with two radial accessory cells; R2-R4 and R5 from apex of accessory cell, M1 from its posterior margin; discal vein concave, M2 arises nearer to M1 than M3. Hind wings with Rs and M1 stalked, discal vein twice angulate, M2 branching nearer to M3 than to M1. External androconial modifications on wings and abdomen absent, pregenital segments not modified, sternite A8 rectangular and slightly longer than sternite A7.

Male genitalia (Fig. 3). Tegumen characteristically longer than vinculum, uncus length about $2 / 3$ of tegumen length. Rudiment of socii as two small hairy pads attached to uncus base. Armature symmetrical. Valva with dentate projection of ventral margin and characteristic concavity between the projection and rounded apex, with an additional small triangular projection in centre of the concavity. Harpe absent. Dorsal arms of vinculum broad and massive, saccus markedly constricted laterally. Aedeagus shorter than valva, straight, one bundle of long
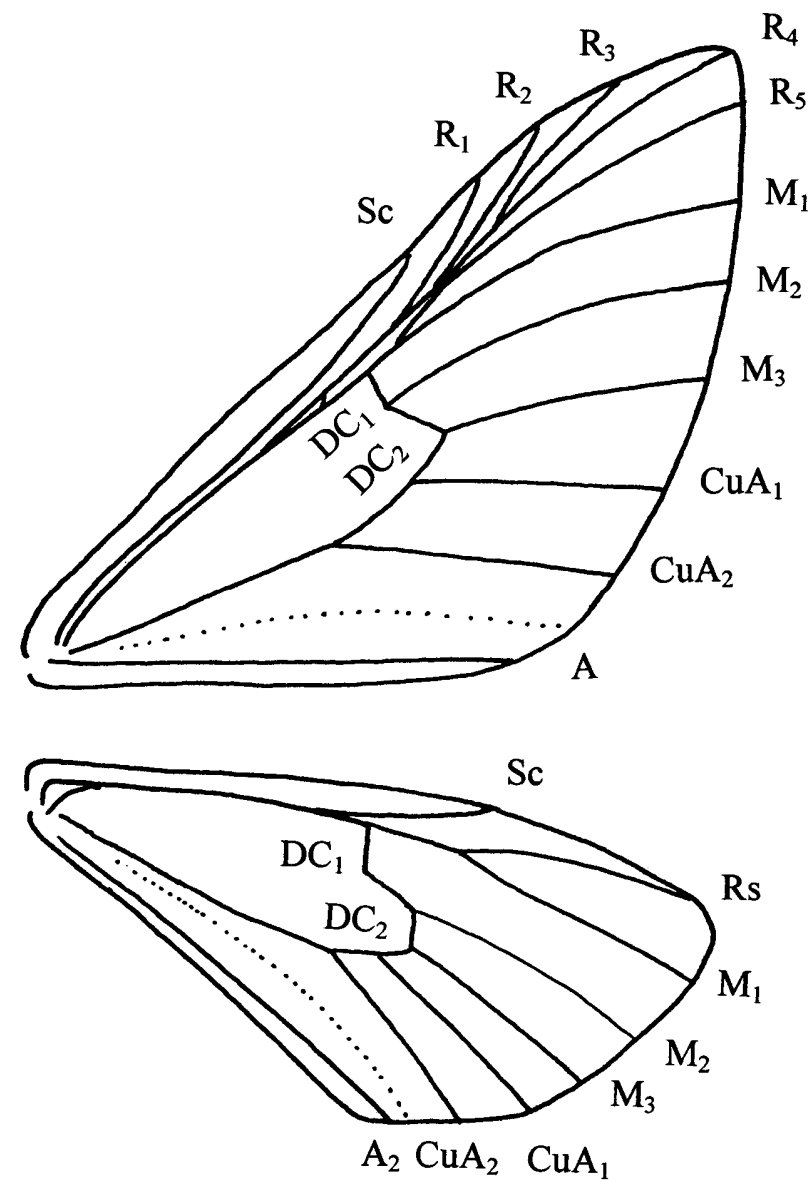

Fig. 2. Pljushtchia prima Viidalepp \& Kostjuk, venation scheme of wings. $\mathrm{DC}_{1}$ and $\mathrm{DC}_{2}$ - anterior and posterior parts of the discal vein.

and one bundle of short spine-shaped cornuti on vesica. Juxta large, plate-shaped, provided with a pair of slender appendages, reaching but not fused to bilobed dorsobasal projections of costa. These lateral appendages of juxta are treated as homologuous with labides.

Female genitalia (Fig. 4). Tergite IX broad, triangular; apophyses anteriores as long as apophyses posteriores; ostium broad, bursa copulatrix very small, membranous, without signum. Total length of female genitalian armature $0.87-0.9 \mathrm{~mm}$.

Etymology. Pljushtchia gen. n. (gender feminine) is dedicated to the collector, lepidopterist I. Pljushtch.

Pljushtchia prima Viidalepp \& Kostjuk, sp. n.

Description (Figs 1-4)

Wing span 23.0-26.0 $\mathrm{mm}$ in males, $21.0-24.0 \mathrm{~mm}$ in females. Thorax and abdomen light brownish grey, posterior margin of first tergite lined blackish. Ground colour of forewing light brown in males; antemedian, median and postmedian lines thin, blackish, surrounded by sparse whitish scales. Antemedian line slightly jagged, median rectangularly broken at Sc towards fore margin of wing, and postmedian line smoothly curved from costa to vein M3. Medial field, between antemedian and postmedian lines, twice as wide as submarginal field. Discal spot con- 


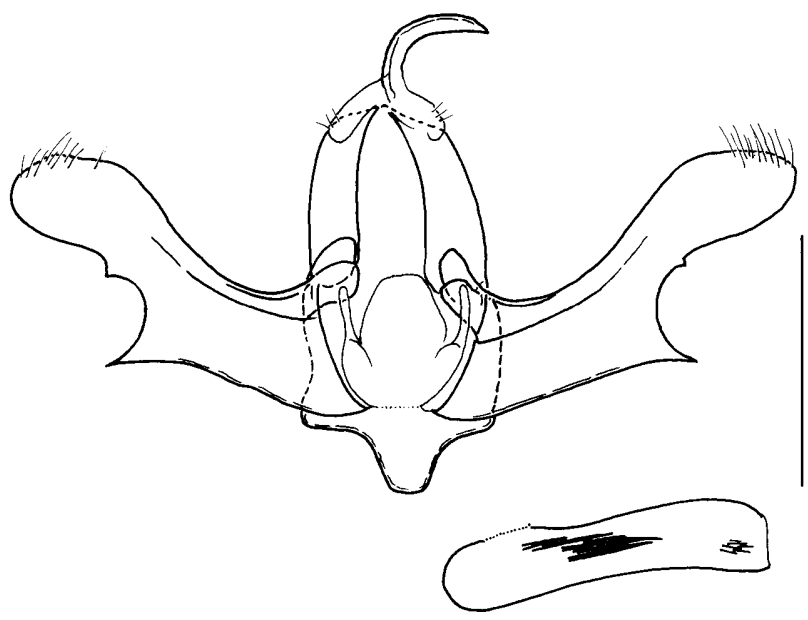

Fig. 3. Pljushtchia prima Viidalepp \& Kostjuk, male genitalia and aedeagus. Scale bar $-1.0 \mathrm{~mm}$.

trasting black, surrounded by a paler patch, apical stripe brownish, weak. Marginal line greyish, cut paler at veins; fringe fairly chequered paler and darker grey. Hind wings light greyish brown with darker greyish brown postmedian band and small blackish cell-spot. Wings colour is darker greyish in males, with transverse lines more contrasting, whereas in females more uniformly lighter brownish. Male and female genitalia: see the description of the genus and Figs 3-4.

Etymology. Pljushtchia prima is the first species in the genus.

Type material. Holotype: $\hat{\delta}$, Tajikistan, Hissar Mts, Kondara valley (1100 m), 30.ix.1979 (I. Pljushtch leg.). Paratypes: 2 \% , same data and locality; 1ठ, 3.x.1979 (I. Pljushtch leg.); 8ठิ, Tajikistan, Hissar Mts, Gushary (village), $1300 \mathrm{~m}$, 10.-25.ix.1965 (Shtshetkin leg.). Holotype and one female paratype deposited at ZBI, two paratypes at ZMKU, and eight paratypes at ZSM.

\section{Analysis of generic characters}

The character spectrum of the described species is rich in apomorphies (bulged frons; unipectinate antennae in male and serrate antennae in female; broad ostium, short ductus and tiny corpus bursae without signum in female). The reduction of palpi and secondary loss of haustellum rarely occur within Larentiinae. Prout (1930-1938) described the reduction of mouthparts in adult moths of some African genera (Conchylidia Guenée, [1858]; Trimetopia Guenée [1858]; Chionopora Prout, 1922) and Janse (1932-1935) recorded this phenomenon in the genus Lycaugidia Hampson, 1895. Species of these genera are confined to arid areas, and we are allowed to assume this character as a phenotypical reaction to environment conditions. Celonoptera Lederer, 1862, a monobasic, systematically isolated genus, confined to the Mediterranean area and having a vestigial haustellum, is probably allied to Trimetopia (Prout, 1930-1938). Similarly, "winter moths" from the genera Operophtera Hübner, [1825] and Malacodea Tengström, 1869, accommodated to activity in unfavourable, cold weather conditions, also have reduced mouthparts.

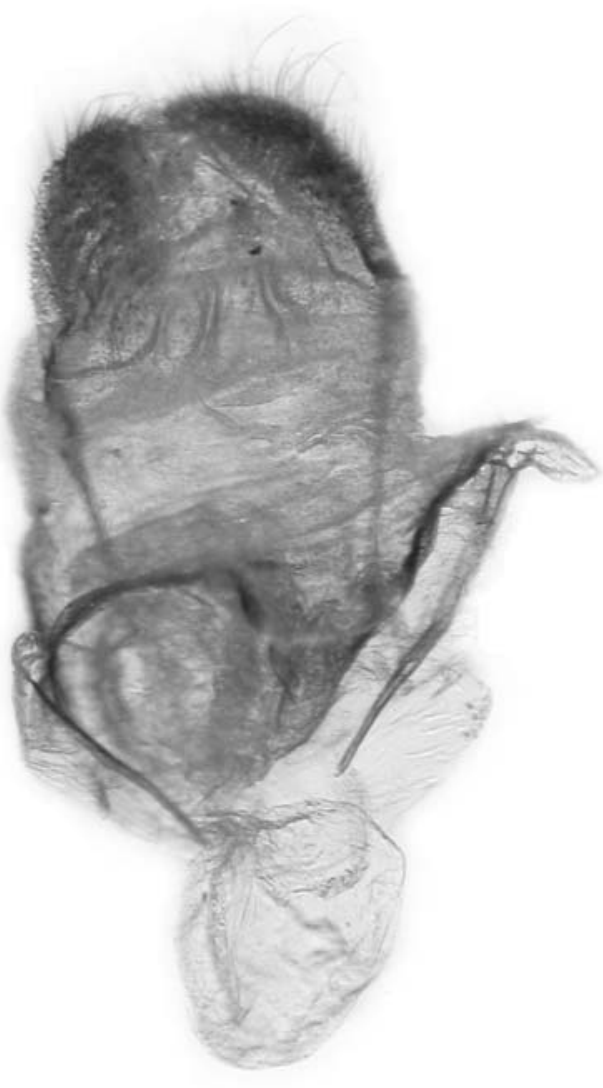

Fig. 4. Pljushtchia prima Viidalepp \& Kostjuk, female genitalia

The shortening of tarsus in male hind leg sporadically occurs in different tribes such as the Trichopterygini, Cidariini (Microlygris Prout, 1914; Hysterura Warren, 1895 a.o.), Solitaneini, and Xanthorhoini (Scotopteryx Hübner, [1825]).

Small hairy pads at uncus base, interpreted as vestiges of socii, occur in the Operophterini and Cidariini (Colostygia Hübner, [1825], Anticollix sparsata (Treitschke, 1828), the Larentiini (Mesoleuca Hübner, [1825]) and Xanthorhoini, being relatively large in Scotopteryx.

A tegumen higher than vinculum and a relatively strong hooked uncus occur in the Larentiini, and in the Cidariini (Heterothera Inoue, 1943, and allied genera). The relatively broad vinculum indicates a plausible relationship with Thera Stephens, 1831 and allied genera of the Cidariini (Cidaria Treitschke, 1825 a.o.), and some Larentiini (e.g. Entephria Hübner, [1825]).

Apophyses posteriores in female are usually twice the length of apophyses anteriores in the Larentiinae, but they appear of the same length in the new genus. However, reduced or shortened anterior apophyses often characterise the Xanthorhoini and Larentiini. The genera of the Larentiini share the presence of a calcar, unpaired, dorsal process of juxta with the Xanthorhoini, but do not have abdominal coremata, which are well developed in the latter. 


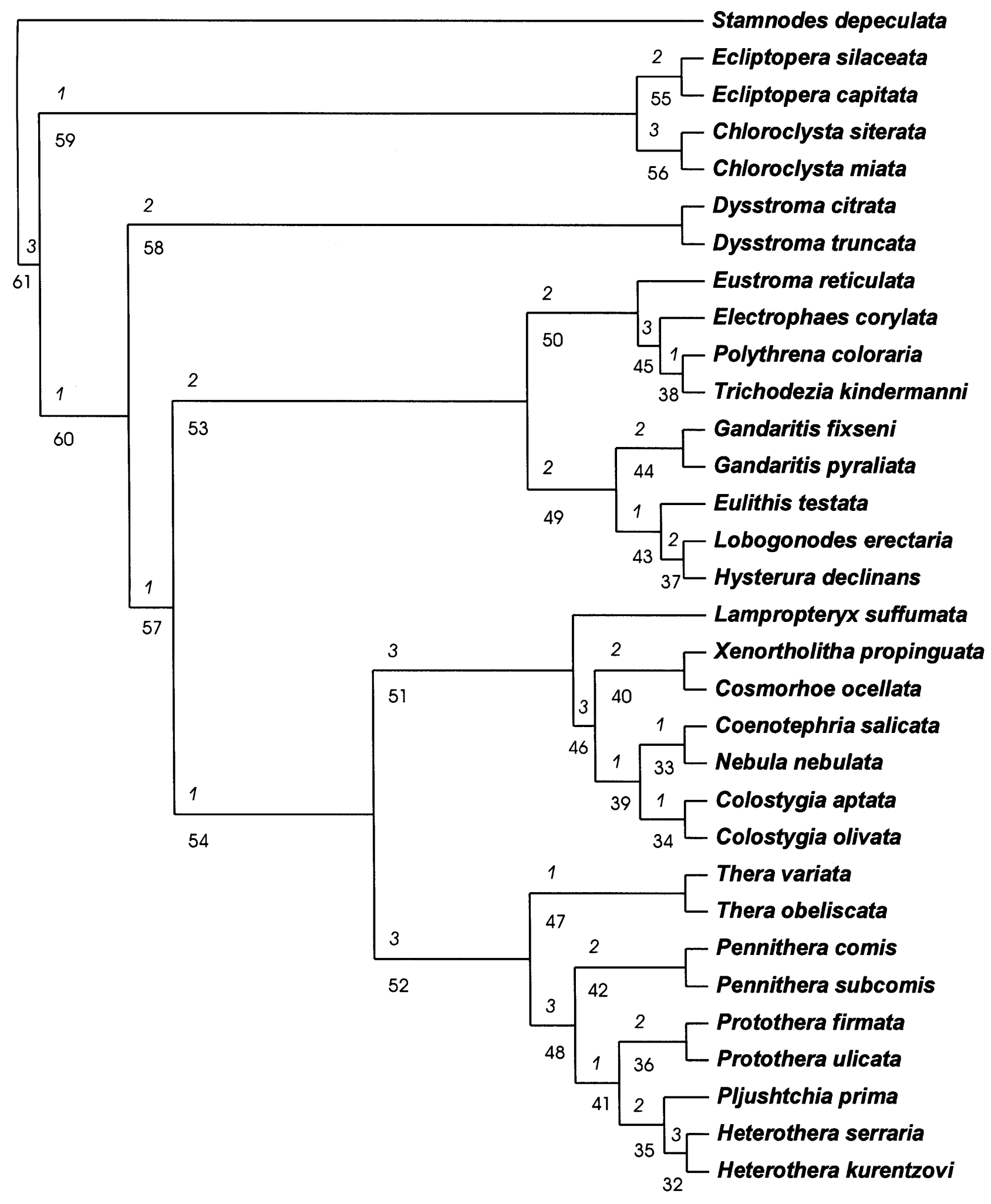

Fig. 5. The cladogram derived from successive weighting approach using Hennig86. The numbers of nodes, below; the number of supporting character state changes, above the node.

A pair of slender appendages arising laterally from juxta, labides, is a synapomorphic character of the Operophterini and Cidariini. These appendages are dorsally fused in the Operophterini, constituting a roof above juxta, but shorter and free in the Cidariini. A large juxta with fair labides in Almeria kalischata (Staudinger, 1870) from the Western Mediterranean is somewhat similar to that in Pljushtchia.

Labides in the tribes Rheumapterini, Melanthiini, Perizomini and Eupitheciini (for the two last tribes, see Miro- 
TABle 1. Comparison of morphological characters of the genera Protothera, Pennithera, Heterothera, Thera and Pljushtchia.

\begin{tabular}{lccccc}
\hline Characters & Protothera & Pennithera & Heterothera & Thera & Pljushtchia \\
\hline Male antennae quadripectinate & quadripectinate & quadripectinate & quadripectinate & fine dentate & unipectinate \\
Male antennae, pectinations & opposite & alternating & opposite & not pectinate & unipectinate \\
Female antenna & filiform & filiform & filiform & filiform & saw-toothed \\
Cornuti in male aedeagus vesica & thin & thick & thick & absent & thin \\
Cornuti around distal opening of aedeagus & absent & absent & absent & present & absent \\
Saccus invaginated & no & no & ventrally & no & laterally \\
Ductus bursae tubular, slender: long or short & no & long, slender & long, slender & long, slender very short \\
Ductus bursae flat, as wide as corpus bursae & flat and wide & no & no & no & no \\
Anterior to antrum heavily sclerotized & no & yes & yes & no & no \\
Ductus and corpus bursae sclerotized & slight & dark & dark & slight & slight \\
Forewing discal mark reaching antemediane & yes & no & no & no & no \\
Interantennal fillet colour & white & dark & dark & dark & variegated \\
Distribution & Mediterranean & East Asian & East Asian & Holarctic & Central Asian \\
\hline
\end{tabular}

nov, 2004) arise from the basal costal corner of the valva, branching dorsally and towards middle of juxta and joining to, but not fusing with juxta.

In summary, we have found characters defining the genus Pljushtchia in various larentiine tribes, but most often in the Cidariini. The shape of juxta in Pljushtchia is typically cidariine.

\section{Cladistic analysis}

The preliminary investigation of wing venation and male genitalia (the presence of labides arising from juxta) allows us to associate the new genus Pljushtchia with the tribe Cidariini. The working hypothesis was checked by a cladistic analysis of the character spectra of 31 ingroup species and Stamnodes depeculata as an outgroup species for tree rooting (see Appendix). Forbes (1948) suggested that the genus Stamnodes Guenée, 1858 is the most primitive among Nearctic Larentiinae.

To substantiate the arrangement of taxa in the Larentiinae volume of the series "Geometrid Moths of Europe", the Eurasian set of genera was analysed preliminarily (Viidalepp, in press). Choi (1997 a.o.) independently published cladistic analyses of some generic groups of the tribe Cidariini, focusing on Thera and allied genera. For comparison he also dealt with Eulithis Hübner, 1821, Ecliptopera Warren, 1894, Dysstroma Hübner, [1825], Chloroclysta Hübner, [1825], Cidaria, and Plemyria Hübner, [1825]. Choi (1997) used four Xanthorhoini species as outgroups, and included 41 species in the ingroup.

The parsimony program Hennig86 v. 1.5 (Farris, 1989) was used to compute a cladogram based on 38 characters of wings venation, external morphology of head, and androconial structures (1-16), morphology of male (characters 17-28, 37) and female genitalia (29-36) (see Appendix). All characters were coded as nonadditive. The parsimony analysis yielded one completely resolved and most parsimonious tree (length 398 steps, ci $=0.70$, ri $=0.83$ ) when the option 'mh' was used and the initial tree was used in successive weighting (two iterations 'xsteps w' with ' $\mathrm{mh}^{*}$ ' and ' $\mathrm{bb}$ ') ). The tree (Fig. 5) was rerooted and visualised by means of the application "Treeview"
(Page, 1996) and studied using the Hennig86 options "xsteps c" and "xsteps h". The support of nodes (Fig. 5 and Table 3) is presented according to Hennig86 option "xsteps h".

The analysis showed the taxa grouped into four main clades. The conifer-consuming species of Thera and allied genera (node 52), and the genera bearing specialised hamuli on labides (node 51) appear placed as most derived sister-clades. Pljushtchia, gen. n. is sister to Heterothera and both sister to Protothera, sharing sclerotised valve costa (character 17), male antennae with pectinations present but not leg-shaped $(12 / 1,13 / 2,3,14 / 1)$, and signum absent or modified in corpus bursae (character $35 / 2$ ). There is no information available concerning food plants of the new species, Pljushtchia prima. The genera in the sister-clade share, besides of the presence of hamuli (character 22/1,2) mentioned above, the presence of a furrow between the valve costa and valvula $(19 / 1,2)$, and vestiture on valves long, arising from ring-shaped structures (20/1). Lampropteryx Stephens, 1831, Coenotephria Prout, 1914, Nebula Bruand, 1846, Colostygia (but not Xenortholitha Inoue, 1944 and Cosmorhoe Hübner, [1825]), share with the Thera-Heterothera clade a biangulate discal vein in hind wings, DC1 longer than DC2 (character 10/2). The separation of Coenotephria (type species: Geometra tophaceata [Denis \& Schiffermüller, 1775]) (with flat, bipartite hamuli) and Nebula (type species: Cidaria nebulata Treitschke, 1828) (with simple, setose hamuli) was proposed by Rezbanyai-Reser (1990) and is discussed elsewhere (Viidalepp, in press). The genera are associated with herbs or deciduous vegetation and are speciose in East Asia. However, Cosmorhoe and Colostygia are confined to the Mediterranean area.

The clade consisting of Eulithis and allied genera (Eustroma Hübner, [1825]; Gandaritis Moore, 1868; Lobogonodes Bastelberger, 1909 and Hysterura) share the presence of hair tufts or specialized scales at forewing base underneath (character $8 / 1,2$ ), thick vestiture on labides, consisting of a mass of thin setae, or hair-like, apically dilated scales (character 26/1) (except Eustroma and Hysterura). The clade is supported by long palpi in 
TABLE 2. Data matrix for one outgroup and thirty-one ingroup taxa. For discussion of characters and character states see Appendix. Characters and states not comparable are coded as hyphen "-", characters with unknown states are coded as question marks "?".

\begin{tabular}{|c|c|c|c|c|}
\hline \multirow[t]{2}{*}{ Taxa } & \multicolumn{4}{|c|}{ Characters and character states } \\
\hline & 1 & 1111111112 & 2222222223 & 33333333 \\
\hline & 1234567890 & 1234567890 & 1234567890 & 12345678 \\
\hline Stamnodes depeculata & 1121001001 & $020-200002$ & $-0-0000000$ & 00100000 \\
\hline Pljushtchia prima & 1121001002 & 0031300100 & 0001100100 & $11002-30$ \\
\hline Eulithis testata & 1221001102 & $010-100020$ & 0011010010 & 01000000 \\
\hline Lobogonodes erectaria & 1122000000 & $110-100020$ & $00110100 ? 0$ & $0100 ? 001$ \\
\hline Gandaritis fixseni & 1222001200 & $010-100000$ & 0021010110 & 01000010 \\
\hline Gandaritis pyraliata & 1221001202 & $010-101000$ & 0021010010 & 01000010 \\
\hline Eustroma reticulata & 1222001101 & $010-000000$ & 0011100110 & 01000001 \\
\hline Hysterura declinans & 1222010110 & $110-000020$ & 0012000010 & 01000000 \\
\hline Coenotephria salicata & 1121101002 & $001-000011$ & 0211001110 & 00100000 \\
\hline Nebula nebulata & 1121101002 & $001-000021$ & 0111001110 & 00101000 \\
\hline Ecliptopera silaceata & 1022101001 & $010-010000$ & 0021100010 & 00100000 \\
\hline Ecliptopera capitata & 1022101001 & $010-000000$ & 0021100010 & 01000001 \\
\hline Polythrena coloraria & 0201001101 & $010-000000$ & 0011100100 & 01002200 \\
\hline Electrophaes corylata & 1122001001 & $020-011000$ & 0021100100 & 01002200 \\
\hline Xenortholitha propinguata & 1022001001 & $010-000010$ & 0111001010 & 00100000 \\
\hline Trichodezia kindermanni & 0222001101 & $010-000000$ & 0011000000 & 01002102 \\
\hline Lampropteryx suffumata & 1222001002 & $010-000011$ & 0211000010 & 00001000 \\
\hline Colostygia aptata & 1121001002 & 0012100011 & 0011101010 & 00100000 \\
\hline Colostygia olivata & 1121001002 & 0012100011 & 0011101010 & 00100000 \\
\hline Chloroclysta siterata & 1122001001 & $010-100001$ & 0021100010 & 01001010 \\
\hline Chloroclysta miata & 1122001001 & $010-100001$ & 0021100010 & 01001010 \\
\hline Dysstroma citrata & 1221001002 & $010-000001$ & 0021000010 & 01000000 \\
\hline Dysstroma truncata & 1221001002 & $010-000001$ & 0021000010 & 01000000 \\
\hline Thera variata & 1221001002 & $010-001200$ & 0011100210 & 00002000 \\
\hline Thera obeliscata & 1221001002 & $010-001200$ & 0011100210 & 00002000 \\
\hline Cosmorhoe ocellata & 1121001001 & $010-000001$ & 0111001100 & 00100000 \\
\hline Heterothera serraria & 0121001002 & 0021001200 & 1000100002 & 12002020 \\
\hline Heterothera kurentzovi & 0121001002 & 0021001200 & 1000100002 & 12002020 \\
\hline Protothera firmata & 1121001002 & 0020001200 & 0011100001 & 02012000 \\
\hline Protothera ulicata & 1121001002 & 0020001200 & 0011100001 & 02012000 \\
\hline Pennithera comis & 1221001002 & 0021001000 & 0011000011 & 00102000 \\
\hline Pennithera subcomis & 1221001002 & 0021001000 & 0011000011 & 00102000 \\
\hline
\end{tabular}

moths, and the genera are associated with deciduous vegetation. Most species belong to the fauna of southeastern Asia, however, Eulithis is widely radiated in the Holarctic.

The basal group of genera includes Ecliptopera, Chloroclysta and Dysstroma, sharing relatively large genital armatures and rich ornamentation on aedeagus vesica. In the dendrogram by Choi (1997, Fig. 46), Dysstroma and Chloroclysta appear as sister-groups and Ecliptopera as the most basal ingroup genus.

Results of the cladistic analysis allow to assume the combination of the new genus Pljushtchia with the tribe Cidariini, using the sequence (Thera (Pennithera (Protothera (Pljushtchia Heterothera)))).
The genus Protothera Viidalepp, 2003 (type species Geometra firmata Hübner, 1822) differs from Thera in quadripectinate male antennae (Table 1). Antennal pectinations are long, slender and branching opposite (shorter, stronger, and branching opposite in Heterothera, slender but branching alternate in Pennithera Viidalepp, 1980) (Choi, 2000). In female genitalia ductus bursae is short, plate-shaped and nearly as wide as corpus bursae; in Thera, Heterothera and Pennithera, ductus bursae is usually tubular and considerably slenderer than the corpus bursae. In some Heterothera species, exceptionally, sterigma, ductus and corpus bursae are heavily sclerotised and dark (Viidalepp, 1980). Seven additional autapomorphic characters listed for P. firmata by Choi (1997) appear to be synapomorphic for Protothera if the sister- 
TABLE 3. Synapomorphic character state changes supporting nodes in the cladogram of the genera of the Cidariini (Fig. 5, and Appendix). Strict synapomorphies in bold.

\begin{tabular}{ll}
\hline Node & Character support \\
\hline 61 & $3(2), 23(1,2), 24(1,2)$ \\
62 & $2(1,2)$ \\
59 & $15(1)(3$ occurrences $)$ \\
58 & $10(2), 20(1)$ \\
57 & $23(1)$ \\
56 & $15(1), 20(1), 37(1)$ \\
55 & $2(0), 5(1)$ \\
54 & $\mathbf{1 0}(2)$ \\
53 & $8(1)$ \\
52 & $\mathbf{1 7}(1), \mathbf{1 8}(1,2), \mathbf{3 5}(2)$ \\
51 & $\mathbf{1 9}(1), \mathbf{2 0}(1), 22(1,2)$ \\
50 & $8(1), 10(1)$ \\
49 & $15(1), 26(1)$ \\
48 & $\mathbf{1 3}(2,3), \mathbf{1 4}(1), 30(1,2)$ \\
47 & $\mathbf{2 8}(2)$ \\
46 & $27(1), 33(1)$ \\
45 & $\mathbf{3 5}(2), \mathbf{3 6}(1,2)$ \\
44 & $\mathbf{8}(2), 37(1)$ \\
43 & $\mathbf{1 9}(2)$ \\
42 & $30(1), 33(1)$ \\
41 & $32(1,2)$ \\
40 & $10(1), 22(1)$ \\
39 & $\mathbf{1 3}(1)$ \\
38 & $8(1)$ \\
37 & $7(0), \mathbf{1 1}(1)$ \\
36 & $30(1), \mathbf{3 4}(1)$ \\
35 & $\mathbf{3 1}(1), \mathbf{3 7}(2,3)$ \\
34 & $\mathbf{1 4}(2)$ \\
33 & $\mathbf{5}(1)$ \\
32 & $\mathbf{2 1}(1), \mathbf{3 0}(2), \mathbf{3 7}(2)$ \\
\hline
\end{tabular}

species of $P$. firmata, $P$. ulicata Rambur, 1834 is included in the matrix and analysis. The position of Protothera and Heterothera + Pljushtchia as sister-groups in the cladogram supports the treatment of the former as an independent genus.

ACKNOWLEDGEMENTS. We thank I. Pljushtch for donation of specimens of the new species to collections of ZBI and ZMKU. Administration of NHM, NMHU, ZFMK, ZISP, ZSM and ZMUC kindly allowed us to study lepidopterological collections. M. Roos kindly revised linguistically the text. Valued comments on the manuscript were received from two anonymous referees. The first author was supported by grants 4085 and 5750 of the Estonian Science Foundation.

\section{REFERENCES}

CHOI S.-W. 1997: Systematics of the Cidariini (Lepidoptera, Geometridae: Larentiinae). University of Helsinki, $178 \mathrm{pp}$.

Chо S.-W. 1998: Systematics of the genus Heterothera Inoue (Lepidoptera, Geometridae: Larentiinae. Tijdschr. Entomol. 141: 19-47.
CHOr S.-W. 2000: A cladistic analysis of the Theriini: A new synonym of the Cidariini (Lepidoptera: Geometridae, Larentiinae). American Museum Novitates No. 3295, 25 pp.

CHOI S.-W. 2001: Phylogeny of Eulithis Hübner and related genera (Lepidoptera: Geometridae), with an implication on wing pattern evolution. American Museum Novitates No. 3318,37 pp.

FARRIS J.S. 1989: HENNIG86: a PC-DOS program for phylogenetic analysis. Cladistics 5: 163.

Forbes J.T.W.1948: Lepidoptera of New York and neighboring states, 2. Memoirs Cornwell University Agriculture Experimental Station No. 274, 263 pp.

Налнімото S. 1995: Taxonomic consideration of three diurnal larentiine genera, Baptria, Trichobaptria and Trichodezia, based on the external structures of the Japanese species (Lepidoptera, Geometridae). Jap. J. Syst. Entomol. 1: 113-124.

JANSE A.J.T. 1932-1935: The Moths of South Africa 2. Geometridae. Durban, 418 pp.

Meijerman L., Tuck K.R. \& DE Vos R. 2000: Arthropods of Economic Importance. Interactive Tutorial for the Preparation of Genitalia in Microlepidoptera. World Biodiversity Database CD-ROM series. UNESCO.

Mironov V.G. 2004: Larentiinae 2 (Perizomini \& Eupitheciini). In Hausmann A. (ed.): The Geometrid Moths of Europe 4. Apollo Books, Stenstrup, pp. 1-403.

Page R.D.M. 1996: TREEVIEW: An application to display phylogenetic trees on personal computers. Computer Appl. Biosci. 12: 357-358.

Pierce F.N. 1914: The Genitalia of the Group Geometridae of the Lepidoptera of the British Islands. By the author, Liverpool, $29+88$ pp., 48 pls.

Prout L.B. 1930-1938: Die spannerartigen Nachtfalter (Fauna Africana). In Seitz A. (ed.): Die Grossschmetterlinge der Erde 16. Alfred Kernen, Stuttgart, 160 pp., 16 pls.

RezbANyAi-Reser L. 1990: Nebula achromaria Lah. und Psodos alpinata Scop.: Berichtigung zu den Genitalabbildungen in Bleszynski 1965-1966 und Forster \& Wohlfahrt 1980 (1981) (Lepidoptera, Geometridae). Entomol. Z. Insektenb. 100(7): 126-131.

Sibatani A., Ogata M., Okada Y. \& Okagaki H. 1954: Male genitalia of Lepidoptera: Morphology and Nomenclature. I. Divisions of the valvae in Rhopalocera, Phalaenidae (= Noctuidae) and Geometridae. Ann. Entomol. Soc. Am. 47: 93-106.

VIIDALEPP J. 1980: Geometrid moths of the genus Thera Stph. in the fauna of the USSR (Lepidoptera). Tartu Riikliku Ülikooli Toimetised 516. Zooloogia-alaseid töid 13: 54-84 (in Russian, English abstr.).

ViIDALEPP J. 1988: [The Geometrid Moths of Mountainous Middle Asia.] Nauka, Moscow, 240 pp. (in Russian).

VIIDALEPP J. 2003: Three different problems with 'Thera' firmata (Hübner, [1822]). XXVI Nordic-Baltic Congress of Entomology. Skalupes, Latvia, July $8^{\text {th }}$ to $13^{\text {th }}$, 2003. Programme, abstracts and list of participants. pp. 39-40.

VIIDALEPP J. (in press): Larentiinae 1. In Hausmann A. (ed.): The Geometrid Moths of Europe 3. Apollo Books, Stenstrup, approx. 550 pp., pls.

Xue D. \& Zhu H. 1999: Lepidoptera Geometridae Larentiinae. Fauna Sinica, Insecta vol. 15. Science Press, Beijing, 1090 pp +25 pls.

Appendix. Characters and character states used in the parsimony analysis (Table 2 and Fig. 5). The character consistency index (ci), and character retention index (ri) of each character in the tree are given in parenthesis.

1. Forewing venation: accessory cells number one (0), or two (1). Prout (1937) subdivided the large genus Cidaria Treitschke, 
1825 (s. lat.) on the basis of the wing venation. Choi (1997, 1998, 2000) did not use venation characters in his cladistic analyses. In spite of that, his results are in good accordance with the genus-level taxonomy by Prout. ( $\mathrm{ci}=0.50, \mathrm{ri}=0.66$ ).

2. Forewing venation: discal vein $(\mathrm{DC} 1+\mathrm{DC} 2)$ straight $(0)$; angulate (1); convex, not angulate (2). The forewing's discal vein is characteristically straight in the tribe Xanthorhoini (Forbes, 1948), but convex or angulate in the Cidariini (with some exceptions: Ecliptopera, Xenortholitha $).(\mathrm{ci}=0.28, \mathrm{ri}=$ $0.66)$.

3. Forewing venation: DC1 as long as DC2 (0); DC1 longer than DC2 (1); DC2 longer than DC1 (2). The trend towards costalisation affects not only the costal area of wings. As a rule, Cidariini genera share DC2 (the lower part of discal vein, between origins of M2 and M3) longer than the upper one, DC1 (between the points of origin of M1 and M2). Exceptions from the common character state occur in some taxonomically isolated monotypic genera (Polythrena Guenée, [1858]). $(\mathrm{ci}=1.00$, $\mathrm{ri}=1.00)$.

4. Hind wing, venation: $\mathrm{DC} 1$ as long as DC2 (0); DC1 longer than DC2 (1); DC2 longer than DC1 (2). The point where the vein $\mathrm{M} 2$ originates in hind wing (nearer to $\mathrm{M} 3$ when $\mathrm{DC} 1>$ $\mathrm{DC} 2$, or nearer to $\mathrm{M} 1$ when $\mathrm{DC} 2>\mathrm{DC} 1$ ) has been used to diagnose larentiine genera (Prout, 1930-1938 a.o.). DC1 equal to DC2 occurs in other tribes of Larentiinae (Lythriini, Aplocerini), not in the Cidariini. $(\mathrm{ci}=0.14, \mathrm{ri}=0.45)$.

5. Forewing venation: $M 1$ connate or stalked with R2-5 (0); M1 free (1). The costalisation of wing venation is a widespread trend among Lepidoptera. Usually, Rs and M1 are stalked in larentiine forewings. Independently arising M1 occurs in Coenotephria and Nebula, and supposedly as parallelism in Ecliptopera (and Sibatania Inoue, 1944, not discussed here in detail). (ci $=0.50, \mathrm{ri}=0.66)$.

6. Forewing venation: $\mathrm{M} 3$ free (0); $\mathrm{M} 3$ stalked with $\mathrm{CuA} 1$ (1). Independently arising veins $\mathrm{M} 3$ and $\mathrm{CuA} 1$ in forewings belong to the groundplan of the Cidariini. Stalked M3 and $\mathrm{CuA} 1$ is a generic autapomorphy of Hysterura. (ci $=1.00, \mathrm{ri}=$ $1.00)$.

7. Hind wing venation: $\mathrm{M} 3$ stalked with $\mathrm{CuA} 1$ (0); $\mathrm{M} 3$ free (1). The basal coalescence of veins M3 and CuA1 is supposedly a symplesiomorphy of Lobogonodes and Hysterura, two small East Asian genera. $(\mathrm{ci}=1.00, \mathrm{ri}=1.00)$.

8. Forewing, underside: specialised scales or hairtufts absent (0); hair tufts present in anal field (1); flecks of specialised scales present near origin of $\mathrm{CuA} 2$ (2). The presence of androconial hair pencils is synapomorphic for Polythrena and Trichodezia Warren, 1895 (Hashimoto, 1995) (also for some Asiatic genera allied to Eustroma), that of specialised scales near the base of $\mathrm{Cu} 2$ is an autapomorphy of Gandaritis. ( $\mathrm{ci}=0.50, \mathrm{ri}=$ $0.60)$.

9. Hind wing, underside: specialised hair tufts absent (0); present at wing base or in anal fold (1). The presence of tufts of hair-like scales on underside of hind wing is supposedly associated with androconial glands. It is a synapomorphy of Pareustroma and Hysterura in the Cidariini. The presence of specialised scales in forewings, hind wings and on sternite VII is an autapomorphy of Trichobaptria Prout, 1914, a monobasic genus similar to Trichodezia (Hashimoto, 1995). $(\mathrm{ci}=1.00, \mathrm{ri}=$ $1.00)$.

10. Hind wing, venation: DC straight or convex (0); DC angulate at origin of M2 (1); DC twice angulate (2). See character 4 above. ( $\mathrm{ci}=0.40, \mathrm{ri}=0.75$ ).

11. Shape of wings: distal margin of both wings smoothly curved (0); distal margin angulate at vein $\mathrm{M} 3$ in hind wings or both wings (1). The character in its derived state is shared by Lobogonodes and Hysterura. $(\mathrm{ci}=1.00, \mathrm{ri}=1.00)$.
12. Male antennae: pectinate, with projections from antennomeres (rami) longer than antenna thick (0); filiform (1); flattened (2). Flat, not cylindrical antennomeres characterise some, not closely related genera: Stamnodes, and Electrophaes Prout, 1914. $(\mathrm{ci}=0.50, \mathrm{ri}=0.81)$.

13. Male antennae: filiform or dentate (0); bipectinate (1); quadripectinate (2); unipectinate-lamellate (3). Dentate antennae (as in Lampropteryx) are coded filiform as it is problematic to delineate them from finely dentate male antennae in Thera. Unipectinate male antennae are a peculiarity of the new genus Pljushtchia. . $(\mathrm{i}=1.00, \mathrm{ri}=1.00)$.

14. Pectinate male antennae: rami long (2.5 times or more the diameter of shaft) (0); rami short, linear (1); rami short, legshaped (dilated apically) (2). The last character state is shared by Colostygia, and Calostigiodes Aubert, 1955 (not included in the recent analysis because of the absence of females in the material studied). Antennal pectinations are longer in Protothera, as compared to those in Heterothera. $(\mathrm{ci}=1.00$, $\mathrm{ri}=$ $1.00)$.

15. Palpus length: palpus moderate $(0)$; palpus long, $3^{\text {rd }}$ segment about one-half length of second segment (1); palpus short, its $3^{\text {rd }}$ segment shorter than one-half length of the second segment, haustellum normal (2); palpus and haustellum both reduced (3). Both shorter (as in Pljushtchia) and longer palpi (e.g. in Gandaritis-Hysterura clade and in Chloroclysta) are coded as deviant from the average length in the Cidariini, the unique reduction stressed in the analysis. $(\mathrm{ci}=0.50, \mathrm{ri}=0.57)$.

16. Eversible abdominal hair pencils: absent (0); present (1). Abdominal androconia occur in Electrophaes and in $E$. silaceata; however, the two genera are not closely related (Fig. 5). $(\mathrm{ci}=0.50, \mathrm{ri}=0.0)$.

17. Male genitalia: sclerotization of valve costa. Costa is sclerotised plate-like, usually gradually fused to valvula (0); or projecting medially or distally (1). Here the gradual fusion of the costa and valvula is hypothesised as a normal situation, leading to simplified structure as, for example, in the tribe Eupitheciini. ( $\mathrm{ci}=0.25, \mathrm{ri}=0.66)$.

18. Male genitalia: distal projection of sacculus. Sacculus is smoothly fused to valvula (0); sacculus not essentially sclerotised, projecting a flat flap (1); sacculus distally sclerotised and projecting acute or hooked (2). $(\mathrm{ci}=0.66, \mathrm{ri}=0.80)$.

19. Male genitalia: relation of costa to valvula on inner wall of valva. The border of costa to valvula demarcated by a longitudinal rib (0); costa and valvula separated by a furrow (1); costa and valvula smoothly fused (2). The presence of lacinia costae (Sibatani et al., 1954) is prevailing within the Cidariini, whereas the presence of a (distally rounded) membranous furrow between the costa and valvula characterises the Lampropteryx-Colostygia clade. The inner wall of valva is well fused in Eulithis, Lobogonodes and Hysterura. $(\mathrm{ci}=0.50, \mathrm{ri}=$ $0.71)$.

20. Male genitalia: vestiture of inner surface of valva. Inner wall of valva without specialised setae and crista hairs (0); numerous long setae present, arising from ring-shaped structures (1); a hair lock arising subcostally (2). An ampulla, bearing a long hair lock, belongs to characters of the Stamnodini. On the other hand, specifically setose valvula is shared by genera of the Lampropteryx-Cosmorhoe clade. $(\mathrm{ci}=0.40, \mathrm{ri}=0.66)$.

21. Male genitalia: vestiture of labides. Labides may be hairy, setose, or provided with a hamulus $(0)$; or sclerotised, bare or fairly short-haired (1). Here the relatively heavy sclerotisation of labides in boreal species of Heterothera is supposed to be derived. The phenomenon embraces not only the informal $H$. serraria group of species but the H. taigana Djakonov, 1926 and related species as well. This state of character seems associ- 
ated with total sclerotisation of female genitalian armatures, see below. ( $\mathrm{ci}=1.00, \mathrm{ri}=1.00)$.

22. Male genitalia: the presence of hamuli. Hamuli (stiff curved setae) absent (0); simple setose hamuli present, surrounded by hairs (1); hamuli are flat and bipartite, bearing a jointed apical segment (2). Simple hamuli in Cosmorhoe, Xenortholitha and Nebula are supposed primitive in comparison to two-segmented ones in Lampropteryx and Coenotephria. However, Colostygia in the same clade lacks hamuli. ( $\mathrm{ci}=0.50$, $\mathrm{ri}=0.33$ ).

23. Male genitalia: vestiture of labides. Labides not hairy (0); hairs localised at apices of labides (1); labides hairy along their inner surface (2). The relatively short and thin vestiture in Pljushtchia and Heterothera is coded as "not hairy". (ci $=0.50$, ri $=0.80)$.

24. Male genitalia: build of labides. Labides absent or not setose (0); present, provided with one patch or row of setae (1); or, bifid and bearing two tufts of long hairs (2). Labides divided bifid and provided with two hair tufts characterise Hysterura (and some other genera in the fauna of East Asia, e.g. Paralygris). Labides of Heterothera are discussed above (character $21)$. $(\mathrm{ci}=0.66, \mathrm{ri}=0.50)$.

25. Male genitalia: length of uncus. Uncus long (as long, or longer than the tegumen) (0); shorter than tegumen (1). A shortening trend of the uncus is possibly homoplasious, although it supports the Ecliptopera-Thera clade. In some cidariine genera as Almeria and Calostigiodes (not included in recent analysis), the distal projection of uncus is entirely absent. ( $\mathrm{ci}=0.16$, $\mathrm{ri}=$ $0.66)$.

26. Male genitalia: vestiture of labides. Labides provided with simple (0); or with androconial hairs (1). Aside of Eulithis, Gandaritis and Lobogonodes, the presence of apically dilated, presumably androconial hairs on labides is also observed in two other East Asian genera: Chartographa Gumppenberg, 1887 sensu Xue Dayong \& Zhu Hongfu (1999), and Eustroma melancholica species group (Choi, 2001) not included in the present analysis. $(\mathrm{ci}=0.50, \mathrm{ri}=0.66)$.

27. Male genitalia: aedeagus shape. Usually straight or curved (0), aedeagus may be sigmoidal or S-shaped (1). S-shaped aedeagi in Coenotephria, Nebula, Colostygia, Xenortholitha, Cosmorhoe and some other genera not discussed in this paper, associate with a peculiar type of female genitalia: see character 33. Lampropteryx, which is placed basally to this clade, has this character less derived. $(\mathrm{ci}=1.00, \mathrm{ri}=1.00)$.

28. Male genitalia: armature on vesica. Cornuti present in aedeagus (0); absent (1); strong thorns present around the distal orifice of aedeagus (2). The latter character state is a peculiarity in Thera Stephens. (ci $=0.28$, ri $=0.37$ ).

29. Female genitalia: shape of bursa copulatrix: membranous, bag-shaped (0); or pyriform (1). Shape of bursa copulatrix varies in the tribe as a whole, but less so by genera. ( $\mathrm{ci}=0.25$, ri $=0.66$ ).

30. Sclerotisation of female genitalian armature. Ductus and corpus bursae membranous (0); ductus bursae sclerotised (1); ductus and corpus bursae heavily and irregularly dark sclerotised (2). Ductus bursae is sclerotised in Pennithera and Protothera species, but the whole bursa or most of its anal part is strong and dark in Heterothera species discussed for the cladogram. ( $\mathrm{ci}=0.66$, ri $=0.75)$.
31. Length of apophyses in female genitalian armature: anterior apophyses present, of medium length or short (0); anterior apophyses reduced (1). Anterior apophyses are short in Heterothera and Pljushtchia. $(\mathrm{ci}=1.00, \mathrm{ri}=1.00)$.

32. Female genitalia: the shape of ductus bursae: tubular, long (0), or short, straight (1); ductus bursae modified (2). Ductus bursae is extremely short in the new genus Pljushtchia (Fig. 4). Ductus bursae is coded modified in Heterothera (strongly sclerotised like also ostium and corpus bursae), and in Protothera (dilated and sclerotised plate-shaped). $(\mathrm{ci}=0.66, \mathrm{ri}=0.92)$.

33. Female genitalia: ductus falling directly in corpus bursae (0); ductus long, tubular, more or less curved S-shaped and falls laterally attached to corpus bursae (1). Coenotephria, Nebula, Colostygia, Cosmorhoe, Xenortholitha have ductus bursae specialised, long, more or less curved S-shaped and sidewise falling in corpus bursae. ( $\mathrm{ci}=0.50, \mathrm{ri}=0.85$ ).

34. Female genitalia: modification of ductus bursae. Ductus bursae shield-shaped, flat (1); ductus bursae tubular (0). Ductus bursae is tubular with ring-shaped sclerotised cingulum in most cidariine genera, and slenderer than corpus bursae even in cases when anal part of genitalia is heavily sclerotised. A short, shield-shaped sclerotised ductus as wide as corpus bursae is a synapomorphy of Protothera species. $(\mathrm{ci}=1.00, \mathrm{ri}=1.00)$.

35. Female genitalia: configuration of signum. Signum oblong or rounded patch of scobination in equatorial part of bursa copulatrix (0); a fish-tail like pattern of scobination, bifurcate at cranial end and tapering posteriorly (1); signum absent or modified (2). ( $\mathrm{ci}=0.40, \mathrm{ri}=0.78)$.

36. Female genitalia: modifications of signum. Signum present as sclerotised longitudinal folds or stripes $(0)$, or sclerotised transversal invaginations (1). Signum as a well-delimited transverse invagination has been known as an apomorphy of Electrophaes (Pierce, 1914; Xue Dayong \& Zhu Hongfu, 1999; Viidalepp, 2003). However, a similar signum is found in Costicoma Choi, 2000 and Polythrena, two isolated Asiatic genera. A pair of sclerotised longitudinal folds in anal part of corpus bursae characterise Trichodezia and Trichobaptria. $(\mathrm{ci}=1.00$, $\mathrm{ri}=$ 1.00).

37. Male genitalia: shape of saccus. Saccus rounded or conical (0); saccus with rounded central invagination (1); vinculum massive, saccus rectangular (2); saccus laterally contracted (3). The build of saccus is relatively uniform in the tribe, relatively strong and massive in Heterothera and allied genera. However, the ventral margin of saccus is invaginated in Gandaritis and Chloroclysta. In Heterothera species treated here, lateroventral corners of saccus are accentuated but the genus also includes species with rounded saccus (Choi, 1997). (ci = $0.60, \mathrm{ri}=0.60$ ).

38. Dorsum of thorax and abdomen without distinct parallel lines (0); both with distinct conspicuous lines (1); tergites black with white transverse lines (2). Conspicuous lining on thorax and abdomen dorsum is shared by Lobogonodes and Eustroma. A broad yellow line characterises Ecliptopera capitata. Abdominal tergites are black with white transverse striation in Trichobaptria, a character sporadically observed in some genera of other tribes as in Epirrhoe Hübner, [1825] (Xanthorhoini) and Rheumaptera Hübner, [1822] (Rheumapterini). (ci = 0.50, ri $=0)$.

Received November 15, 2003; revised and accepted July 14, 2005 